\title{
La Cesantía Comercial Elemento Determinante Del Contrato De Agencia
}

\author{
The unemployment determinant commercial agency agreement
}

FRANZ LEONARDO MARCELO BEDOYA RUBIO

Abogado egresado y Especialista en derecho comercial y de los Negocios

Universidad Santo Tomas de Aquino Bogotá DC. Estudios de posgrado en derecho contractual en la universidad del Rosario, facultad de jurisprudencia. Candidato a Magister en Derecho Contractual Público y Privado Universidad Santo Tomas de Aquino. Docente Universidad Cooperativa de Colombia. Correo

Electrónico: bypconsultores@hotmail.com

Graduated and specialized in commercial law and Business University of Santo Tomás Bogotá DC. Postgraduate studies in contract law at the University of Rosario, School of Law. Candidate for Master in Public and Private Contract Law University of Santo Tomás. Professor Cooperativa University in Colombia. EMail: bypconsultores@hotmail.com

Fecha de recepción: 30 de marzo de 2011 Fecha de evaluación: 15 de abril de 2011 Fecha de aprobación: 13 de junio de 2011

Resumen: El contrato de agencia comercial es una de las principales figuras jurídicas utilizadas para la intermediación comercial tanto nacional como extranjera, configurándose en una institución jurídica de total importancia para el crecimiento económico del país. Una de las características esenciales del contrato de agencia comercial es la estipulación de la indemnización y la denominada cesantía comercial establecidas en el artículo 1324 del código de comercio. 
El contratante o agenciado, ha buscado diferentes mecanismos para evitar el pago de la indemnización y la cesantía establecida en el artículo referenciado; lo cual ha generado una desnaturalización del contrato de agencia comercial, convirtiendo la relación jurídica de la agencia comercial en una tipificación contractual totalmente diferente.

La globalización y la internacionalización ha llevado entonces a que de una u otra forma las empresas extranjeras como las nacionales pretendan desconocer en ciertos negocios, el carácter de orden publico por encima de la voluntad de las partes.

Palabras Clave: contrato de agencia comercial, contrato de intermediación, contrato de colaboración, cesantía comercial, indemnización, distribución, suministro.

Abstract. The commercial agency contract is one of the major legal figures used for brokering domestic and foreign trade, configured in a legal institution of total importance for the country's economic growth. An essential feature of the agency contract business is the provision of compensation and called commercial severance provided for in Article 1324 of the commercial code. 
The contractor or agency, has sought different mechanisms to avoid paying compensation and severance set forth in the referenced article, which has created a distortion of the agency contract business, becoming the agency's legal relationship business in a fully contractual definition different.

Globalization and internationalization has led to one or another form of foreign and domestic companies seeking to disregard in certain businesses, the nature of public policy over the will of the parties.

Key words: commercial agency contract, contract intermediation, cooperation agreement, severance business, compensation, distribution, supply.

Tipo de Artículo: Reflexión Académica

\section{INTRODUCCIÓN}

Los mercados son la sustancia de la globalización económica. Los mercados que emergen en una era globalizada tienden a ser independientes del poder del estado, dado que las tendencias económicas del presente pregonan la mínima injerencia de aquel en el mercado por considerar que este es mejor asignador de recursos. 
En este orden de ideas, muchas empresas extranjeras, o fabricantes nacionales, entran a conquistar mercados en territorios ajenos a sus países de origen, o en su propio territorio nacional, con el objeto de llevar sus productos al consumidor. Para ello existen varias opciones: constituir un departamento de ventas propio, o buscar distribuidores y/o agentes que coloquen sus productos en el mercado. Aquí cobra importancia vital la forma contractual, toda vez que a partir de ella se van a generar los negocios que reportarán el fin último en el objeto de la empresa agenciada: la utilidad. La primera de las opciones mencionadas no siempre es la más indicada por cuanto las empresas fabricantes o multinacionales, se ocupan primordialmente de la fabricación de sus productos lo cual hace que no les interese abrir agencias propias de mercadeo ya que ello causa una desviación de su objeto social, así como asignaciones de tareas que pueden interferir con este objeto (contratación de personal, departamento de finanzas, talento humano, publicidad y costos de distribución.

De ahí que la contratación de agentes sea la opción más indicada en la mayoría de los casos, pues a través de esta figura, la empresa agenciada tiene la facilidad de ocuparse libremente de su objeto social debiéndose preocupar solamente por colocar sus productos en manos de su agente o distribuidor quien, finalmente, lo llevará a las manos del consumidor. Las ventajas de tal opción son enormes, pues es el agente quien debe encargarse bajo su propia cuenta, riesgo y costo, de colocar los productos de la empresa proponente en el mercado, es decir, de conquistar un lugar en la escala de bienes y servicios. 
No obstante, la costumbre de estas empresas agenciadas ha sido la de conquistar mercados a través de agentes comerciales, los cuales colocan los bienes y servicios a nivel territorial logrando así una excelente posición económica, para después romper injustificadamente el vinculo contractual con el agente en detrimento de la empresa, utilidad y nombre de este, construidos alrededor y como causa de la distribución de los productos del agenciado. No satisfecha con ello la empresa agenciada, tiende a argumentar que los contratos celebrados con los agentes no son de agencia comercial, tendiendo con ello a eludir el pago de la prestación del artículo 1324 del código de comercio denominado "Cesantía Comercial", cuya razón de ser ha sido precisamente resarcir al agente por la terminación intempestiva del contrato y por los costos que puede generarle la terminación definitiva de un vinculo comercial a través del cual ha creado un nombre, conquistado una clientela e incurrido en gastos por tal causa.

Actualmente, las empresas agenciadas se presentan ante los operadores de justicia argumentando que los contratos celebrados con sus agentes son de distribución. Su argumento radica en que el contrato de distribución no tiene lineamientos claros contenidos en la ley por ser un contrato atípico. La salida a este inconveniente por parte de las empresas agenciadas o fabricantes, ha sido el de alegar la existencia de otra modalidad contractual de intermediación distribución, concesión, preposición, comisión, corretaje, suministro y consignación, para así eludir el pago de la prestación aludida en el art. 1324. 
La presente investigación pretende deslindar minuciosamente los elementos de la cesantía comercial con el fin de elaborar conceptos que pongan freno a esas arbitrariedades en que incurren las empresas multinacionales (o fabricantes nacionales) al momento de poner en circulación sus bienes a través de los agentes comerciales. La doctrina y la jurisprudencia no han sido claras en el tratamiento de esta figura, al punto en que hoy día se discute si la cesantía comercial es renunciable o irrenunciable, si la naturaleza de la agencia comercial le permite transformarse en otro contrato o si existen razones de peso para permitir que una empresa se enriquezca injustamente a expensas de quien ha colocado sus productos en el mercado.

\section{MATERIALES Y MÉTODOS}

\section{Diseño}

El presente artículo fue diseñado siguiendo los parámetros establecidos por el método de investigación cualitativo de tipo revisión documental de las normas y jurisprudencia sobre los contratos de agencia comercial, con aplicación de casuística relacionada a la temática. 


\section{Entorno}

El presente artículo se efectuó durante la realización de la Maestría en Derecho Contractual Público y Privado realizada en la Universidad Santo Tomas de Aquino Facultad de Derecho.

\section{Participantes}

Un estudiante de la Maestría en Derecho Contractual Público y Privado de la Universidad Santo Tomas De Aquino, Facultad de Derecho

\section{CONTRATO DE AGENCIA COMERCIAL}

El contrato de agencia comercial constituye una forma de intermediación empresarial. Es un negocio jurídico de carácter bilateral, oneroso, consensual, principal, de libre discusión, nominado y se encuentra regulado por nuestro ordenamiento comercial colombiano en el artículo 1317.

Al interior de la legislación nacional fue recogido por primera vez en el código de comercio de 1971 y su formulación final fue la resultante de la amalgama de dos proyectos diferentes, a saber, el proyecto de reforma al código de comercio que databa de 1958 y un proyecto de ley radicado ante la cámara de representantes en 1969. 
El contrato de agencia comercial se encuentra establecido en el artículo 1317 del código de comercio colombiano de la siguiente manera:

Por medio del contrato de agencia, un comerciante asume en forma independiente y de manera estable el encargo de promover o explotar negocios en un determinado ramo y dentro de una zona prefijada en el territorio nacional, como representante o agente de un empresario nacional, o extranjero o como fabricante o distribuidor de uno o varios productos del mismo.

La persona que recibe dicho encargo se denomina genéricamente agente.

La jurisprudencia nacional ha manifestado que este contrato “(...) constituye una forma de intermediación; que el agente tiene su propia empresa y la dirige independientemente; que su actividad se encamina a promover o explotar negocios en determinado territorio, es decir, a conquistar, ampliar o reconquistar un mercado en beneficio del principal, a quien puede relacionar con los clientes, o actuar como su representante, agente, fabricante o distribuidor, actividades que en todo caso deben estar dirigidas a la explotación de los negocios del empresario; que requiere de estabilidad en el desempeño de su labor y da lugar a remuneración".

Siendo así, no cabe la menor duda de la necesidad indiscutible de la determinación de los aspectos elementales que permiten la configuración de la agencia comercial, por un lado desde el punto de vista subjetivo, la configuración 
de la agencia comercial lo conforman dos grandes intervinientes, a) el agente, quien de acuerdo a nuestra normatividad es aquel comerciante quien recibe el objeto primordial del contrato, es la persona en la cual recae la actividad que se encamina a la apertura del mercado en determinada zona del comerciante 0 empresario productor del bien o del servicio prestado; y b) el agenciado, el cual en la gran mayoría de oportunidades se encuentra desarrollado por una sociedad comercial o una empresa la cual se encuentra totalmente habilitada para la celebración de negocios jurídicos, la cual decide expandir el ámbito territorial encargando para ello la función de apertura del comercio y de la clientela, generando así nuevas relaciones contractuales entre el agente y los consumidores, estos últimos los cuales pueden llegar a ser, los beneficiarios directos u otros pequeños distribuidores.

Según Arce Gargollo (2007), La denominación del aspecto subjetivo del contrato de agencia comercial en otros países ha sido desarrollado de tal manera que permita identificar la relación jurídica material, caso puntual es la legislación comercial mexicana en donde se desarrolla este aspecto manejando los términos respectivos de agente, comitente, mandatario o representante y por otro lado empresario, principal, mandante o representado. De acuerdo con el mismo autor, la legislación civil italiana la denomina y utiliza los términos de preponente o empresa y agente, en la legislación francesa los agentes comerciales se les llaman mandante y mandatario, en la ley española se denomina como agente y empresario. (Pág.344). 
De otro lado los elementos constitutivos de la agencia comercial desde el punto de vista objetivo en nuestra legislación comercial han sido, igualmente, materia de tratamiento por la jurisprudencia nacional.

El contrato de agencia comercial, por tanto, se caracteriza por un conjunto de elementos básicos que se pueden concretar así:

1. El agente es un promotor de negocios, de clientela y de contratos; el agente se obliga a lograr la celebración de contratos para el fabricante; es su obligación principal, en tanto que, la del fabricante es pagar una comisión sobre los contratos logrados por la intermediación del agente. La actividad de aquél se traduce en una prestación de hacer mientras éste asume una prestación de dar unas sumas de dinero, que se derivan de las comisiones ganadas por la conclusión de los contratos gracias a la cooperación e intermediación del agente.

Existen otras obligaciones accesorias del fabricante o agenciado y del agente. Para aquél la de no realizar ventas directas y para éste las de organizarse patrimonial y autónomamente, hacer propaganda, cumplir instrucciones, y dar información sobre la situación económico-financiera del sector y los datos esenciales para adecuar las políticas comerciales al lugar de ejecución de las operaciones del agente. 
2. Es fundamental que aparezcan detallados los bienes y servicios cuya promoción o venta asume el agente.

3. Debe aparecer limitada la zona de actuación del agente, es decir el ámbito espacial de actuación, que puede ser exclusivo, en cuyo caso se prevén las consecuencias que para el empresario o fabricante se producen por la vulneración del derecho de exclusividad.

4. Entre las facultades del agente está la de cerrar operaciones en nombre y por cuenta del empresario o solo comunicarle los pedidos, con la reserva de éste de rehusar o aceptar las operaciones y concluirlas.

5. La actividad del agente la desarrolla con autonomía, es decir, sin dependencia del empresario y de manera estable por cuanto se extiende en el tiempo y no para promover un negocio o contratación aislada.

6. Debe aparecer determinada la forma de remuneración del agente, la cual nace de cada negocio celebrado mediante su intervención.

El dinamismo de la actividad comercial ha obligado al derecho a tratar de regular, los variados comportamientos comerciales o negocios jurídicos en diferentes contratos, denominados por la doctrina como contratos de intermediación empresarial o contratos de colaboración empresarial. 
Sin embargo y para poder analizar el contrato de agencia comercial en todo su contexto es necesario verificar la variedad de aportes jurisprudenciales al respecto. En este sentido la corte suprema identifico la agencia comercial de la siguiente manera:

"como es sabido, en razón de las necesidades surgidas por el auge de la vida de los negocios, el derecho ha regulado las actividades de intermediación, las cuales han dado origen a nuevas modalidades contractuales, entre las cuales se encuentra la agencia comercial, como aquel en que una persona en forma independiente y estable asume bajo remuneración el encargo de promover o explotar negocios en un determinado ramo y dentro de una zona prefijada en el territorio nacional, como representante o agente de una empresa nacional o extranjero o como fabricante o distribuidor de uno o varios productos del mismo; contratos estos específicamente incluidos en la legislación colombiana.( Díaz Rueda, 2008, Pág.19).

El dinamismo de la actividad comercial ha obligado al derecho a tratar de regular los variados comportamientos comerciales o negocios jurídicos en diferentes contratos, denominados por la doctrina nacional y extranjera como contratos de intermediación empresarial o contratos de colaboración empresarial. Entre esta clase o diversidad de negocios jurídicos, encontramos una gama de contratos que han sido identificados claramente por el autor Mexicano Alejandro Arce Gargollo, en su obra "Contratos Mercantiles Atípicos" y los enumera de la 
siguiente manera: a) el contrato de distribución, b) contrato de consignación o estimatorio, c) contratos de arrendamiento financiero, d) contrato de factoraje, e) contrato de comisión, f)el contrato de corretaje o mediación, g) contrato de agencia, h) contrato de distribución, i) el contrato de franquicia, j) el contrato de join venture, k) el contrato de exclusiva y la clausula de no competir.

Sin embargo aunque el contrato de agencia comercial tratado por el autor, para el derecho mexicano es atípico, ha sido considerado dentro de los denominados contratos de intermediación empresarial, dada su importancia y relevancia en el mundo de los negocios mercantiles de carácter nacional e internacional.

En el ámbito colombiano Arrubla Paucar (2005), ha señalado a los contratos de concesión o distribución comercial, a) contrato de comisión, b) contrato de mediación o corretaje y c) el contrato de agencia comercial como contratos de intermediación empresarial. Así mismo Bonivento Jiménez (1999), en su obra contratos mercantiles de intermediación los clasifica como, a) representación, b) mandato, comisión, preposición, c) agencia comercial y corretaje.

Vale la pena señalar que el contrato de agencia comercial en Colombia es típico a diferencia de la legislación mexicana, pero típica en otros países como en: "el código de comercio alemán (1897) es el primer ordenamiento que lleva a cabo 
una regulación completa de este contrato. El código civil italiano (1942) lo reglamenta como un contrato distinto al mandato y a la comisión, el código suizo de las obligaciones define al agente y contiene normas sobre el contrato de agencia, en Francia por decreto de 29 de diciembre de 1958, se establecen disposiciones relativas a los agentes comerciales y se reglamenta al contrato de agencia, en España se promulga la ley sobre el contrato de agencia (1992) con normas inspiradas en la directiva de la comunidad económica europea, esta figura contractual también se contempla en el código de comercio de Colombia y, en la legislación de Bolivia se regula con otras figuras como la comisión, la representación y la distribución". (Arce Gargollo, 2007).

De las operaciones mercantiles desarrolladas por los comerciantes en el ámbito nacional o internacional, en el intercambio de bienes y servicios, surge la necesidad a los contratantes de encontrar la manera mas adecuada de regular dichas operaciones comerciales.

En el derecho mercantil como "categoría histórica", "la intermediación es una actividad común y de gran importancia. Originalmente esta rama del derecho privado nació para regular el comercio, que es sinónimo de intermediación. "el comercio es el conjuntó de actividades que efectúan la circulación de los bienes entre productores y consumidores" (Arce Gargollo, 2007). 
En el contexto nacional e internacional la globalización de la economía ha llevado a que los mercados ofrezcan alternativas negóciales a fin de lograr la comercialización de sus productos en calidad de fabricante o de intermediario.

En la economía de hoy la mayoría de los productores no venden sus artículos directamente a los usuarios finales. Entre unos y otros se alza una legión de intermediarios de mercadotecnia que desempeñan gran variedad de funciones y ostentan gran variedad de nombres: corredores, representantes, mayoristas, distribuidores, cooperativistas, comerciantes al detalle, entre otros. (Kotler, 1966, citado en Arce Gargollo, 2007)

Ante la imperiosa necesidad de buscar una alternativa jurídica que regule las relaciones contractuales entre productor y consumidor final, las partes adoptan de las diferentes modalidades de intermediación comercial, la que para ellos mas les favorezca o le favorezca, ya que de allí surge el interrogante objeto de este estudio, en cuanto a que en el momento negocial, en las tratativas del negocio jurídico, las partes adoptan bajo los preceptos del principio de buena fe contractual un lado opuesto frente al otro haciendo un singular paralelo, entre lo que quieren cada uno en el extremo opuesto.

Es decir, una vez concretado el negocio jurídico, los contratantes, deben procurar claridad en el clausulado del negocio de tal modo que no se presenten inequívocos de tal forma que pueda afectar el negocio pactado. 
En desarrollo de lo anteriormente escrito, se presenta la dificultad jurídica en el sentido de verificar la figura jurídica contractual más favorable para las partes.

Esto es de la gama de contratos de intermediación comercial, escogerán la denominación contractual mas adecuada para cada quien.

En lo que corresponde a la finalidad económica que se procura satisfacerse mediante el contrato, se ha señalado que "cuando un empresario desea extender en forma masiva o constante su actividad en una zona, no recurra a un comisionista, sino a dos posibles y distintas formas de colaboración: crear una sucursal o delegación propia que, integrada en su empresa y con dependencia económica y jurídica de ella, promueva su actividad contractual y captación de clientela en su nombre y por cuenta de aquel; o, por el contrario, nombrar a un agente quien con su propia empresa, en forma jurídica y económicamente independientes y, por ende, fuera de la empresa del empresario representado, se dedica profesionalmente a captar clientela para el, bien mediante su simple promoción o bien por medio de la conclusión de contratos por cuenta, en nombre e interés de aquel”.(Broseta ,2003 Pág. 503)

Bajo esta perspectiva, se ve demostrada la adecuación del contrato tipo ajustado al momento del negocio jurídico. No obstante lo anterior, en los contratos es valido hacer una valoración del querer de las partes, bajo el principio de la 
autonomía de la voluntad, y entender hasta donde se puede extender la voluntad contractual, en el sentido de llevar a la renuncia de comisión o indemnización en caso de terminación unilateral del contrato por una de las partes.

Uno de los contratos comerciales que mayor actividad litigiosa ha generado en Colombia en los últimos 15 años es el de la agencia comercial.

Siendo la agencia una de las especies principales dentro del genero de los contratos de colaboración empresarial, fue sometida, por el código de comercio de 1971, a un régimen comercial de protección para el agente, materializado en la llamada cesantía comercial a la terminación del contrato y en la protección especial, mediante indemnización equitativa, frente a la terminación unilateral injustificada por parte del empresario agenciado". (Revista Portafolio, 2005)

El triunfo de los negocios logrado por muchos empresarios he tenido sustento en la forma adecuada del manejo de sus finanzas acompañada de buenas decisiones empresariales, bajo la perspectiva de un pleno conocimiento de las reglas de juego en determinada nación o región en el que desempeñe su actividad empresarial.

Cuando se habla de reglas de juego se puede tocar el tema del conocimiento de la legislación en el lugar en donde la empresa quiera tener presencia comercial. En esa expansión empresarial el productor se ve avocado a 
buscar socios estratégicos o formulas ideales para lograr ingresar en determinado mercado buscando siempre las mejores opciones y tratando de aminorar riesgos que no afecten su caja o estabilidad financiera.

En el mismo sentido se ha señalado: "el empresario ya no podía asumir directamente todos los negocios que se relacionaban con su actividad. La producción en masa había impuesto la comercialización en masa. Aquel requería una persona que se dedicara de manera permanente y estable a promover sus negocios en otras plazas. No le bastaba el comisionista cuya vinculación con el empresario era, por lo general, transitoria. Ante este imperativo, podía optar por dos soluciones. En primer lugar, colocar en tales plazas un empleado que dedicara a fomentar sus negocios y, eventualmente, a celebrar sus contratos. Esta solución era práctica en aquellos lugares donde el empresario tenía ya una situación definida y desarrollaba un considerable número de negocios. En segundo termino, el empresario podía contratar con alguna persona para que, de manera independiente y estable, asumiera la promoción de sus negocios; surge entonces la figura del agente”. (Cárdenas, 2003, Pág. 5).

De la naturaleza jurídica del contrato se desprende la figura de la cesantía comercial, acompañada de la indemnización de perjuicios, "articulo 1324 del código de comercio: el contrato de agencia termina por las mismas causas del mandato, y a su terminación el agente tendrá derecho a que el empresario le pague una suma equivalente a la doceava parte del promedio de la comisión, 
regalía o utilidad recibida en los tres últimos años por cada uno de vigencia del contrato, o al promedio de todo lo recibido, si el tiempo del contrato fuere menor.

Además de la prestación indicada en el inciso anterior, cuando el empresario revoque o de por terminado unilateralmente el contrato, sin justa causa comprobada, deberá pagar al agente una indemnización equitativa, fijada por peritos como retribución a sus esfuerzos para acreditar la marca, la línea de productos o los servicios objeto del contrato" (Tafur Galvis, 2006).

Tal vez esta es la razón jurídica por la cual las compañías extranjera o nacionales dependiendo el esquema de negocios en que se encuentre, tratan de evitar al máximo el pago de la cesantía comercial al agente, a la persona que de una u otra manera se ha encargado principalmente de la expansión del negocio.

Así las cosas, en el contrato de agencia mercantil encontramos que esa labor de promoción y/o explotación de negocios que realiza el agente de manera independiente, estable y remunerada, la realiza por del cuenta del agenciado, lo cual significa que las consecuencias jurídicas, los efectos jurídicos de los actos ejecutados por el agente, así no sea representante del empresario, se trasladan o deben trasladarse a la orbita patrimonial del empresario, quien es el llamado a asumir los (i) riesgos de dichos actos tales y como la perdida o no venta de la mercancía, la cartera morosa, así como (ii) las ventajas de las actuaciones y 
operaciones realizadas por el agente. (Holguín Neira \& Pombo abogados, Bonivento, 1999, Pág. 140 y 141.)

Como quiera que del contrato de agencia comercial surge el pago de la cesantía comercial junto con el de la indemnización de perjuicios, el agenciado, examina la manera de evitar dicha erogación.

Por lo tanto y una alternativa para esquivar dicho costo agregado busca otra forma o modelo contractual que le ofrezca las garantías jurídicas suficientes para que en caso de terminar el contrato de forma unilateral no tenga esa carga económica a favor del agente.

Cárdenas, (2003), resalta que en general el espíritu del legislador aparecía alentado por dos móviles fundamentales. De una parte la protección a los comerciantes frente a los abusos de otros empresarios, generalmente extranjeros; y adicionalmente evitar que se hiciera fraude a la legislación laboral a través de la celebración de contratos de distribución simulados .

Es decir una de las formas de simular, disfrazar o evitar la configuración de un contrato de agencia comercial, es logrando la desnaturalización del contrato, pactando un contrato de letra muerta, ya que en la realidad no es lo realmente querido por las partes. 
Las partes consideraron en el escrito que documento el contrato existente entre ellas que se trataba de un contrato atípico, al cual no se le aplicaban las normas del contrato de agencia, no obstante las anteriores manifestaciones, es deber de este tribunal determinar el derecho aplicable a los hechos sometidos a su conocimientos y calificar jurídicamente la naturaleza del contrato objeto de examen. La posibilidad e incluso el deber de hacerlo han sido reiterados desde vieja data por la jurisprudencia:

"la calificación que los contratantes den a un contrato, motivo del litigio no fija definitivamente su carácter jurídico; mejor dicho, las partes no pueden trocar ese contrato en otro por el mero hecho de darse un nombre" ( sentencia del 9 de septiembre de 1929, G:J:, tomo XXXVII, Pág. 128).

“...los pactos no tienen la calidad que les den los contratantes, sino la que realmente les corresponde" (sentencia del 28 del julio de 1940, G.J: tomo XLIX, Pág. 574).

En la labor del interpretación de los contratos no debe olvidar el juez, de otra parte que la naturaleza jurídica de un acto no es la que las partes que lo realizan quieran arbitrariamente darle, ni la que al fallador le venga en gana, sino la que a dicho contrato corresponda legalmente según sus elementos propios, sus calidades intrínsecas y finalidades perseguidas”(Murcia Ballén, 1984, Pág. 254). 
El comercio nacional colombiano contiene un aspecto de total trascendencia; queriendo así referenciar que la distribución de los bienes y servicios ofrecidos por las diferentes compañías, es indispensable el apartamento e identificación puntual de aquellas compañías generadoras de bienes y servicios dejando en manos de compañías ajenas a ella el manejo de la distribución comercial de sus productos.

La regulación comercial entre lo ofrecido por el empresario y la vida económica, se ve envuelta en la capacidad existente de despliegue que pueda generar el empresario sobre sus productos creando un equilibrio entre los intervinientes de dicha actividad.

La existencia de tan diversas instituciones contractuales algunas de ellas típicas y en otros casos atípicas como la de la distribución, dichos mecanismos son constitutivos desde el punto de vista mas elemental, la utilización de la figura del mandato mediante el cual una persona, en nuestro caso una empresa efectúa un negocio jurídico a favor de otro consistente en la ejecución de ventas de sus productos o servicios a fin de lograr el ingreso de bienes y servicios a determinado mercado. La pregunta que se genera es la relación jurídica subjetiva existente entre el mandatario y el mandante, en donde el mandatario es un simple gestor ejecutante de los intereses del mandante, el cual según el consentimiento de las partes puede llegar o no a tener su representación, configurándose así una posibilidad vetusta de un sistema de distribución. 
"Como es sabido, en razón de las necesidades surgidas por el auge de la vida de los negocios, el Derecho ha regulado las actividades de intermediación, las cuales han dado origen a nuevas modalidades contractuales, entre las cuales se encuentra la agencia comercial, como aquél, en que una persona en forma independiente y estable asume bajo remuneración el encargo de promover o explotar negocios en un determinado ramo y dentro de una zona prefijada en el territorio nacional, como representante 0 agente de un empresario nacional o extranjero o como fabricante o distribuidor de uno o varios productos del mismo; contratos éstos específicamente incluidos en la legislación colombiana”.( Díaz Rueda, 2008)

Son muchas las posibilidades de implementación de contratos camuflados a fin de evitar el proteccionismo de la legislación comercial de la figura de la agencia comercial, para ello se hace indispensable establecer los elementos de la naturaleza de cada contrato en particular, para luego verificar un paralelo entre una y otra figura contractual.

Si bien es cierto los contratos de intermediación comercial son muy afines, también es cierto que cada uno difiere del otro, por ello es necesario establecer algunas diferencias entre los contratos mencionados: "en el contrato de agencia comercial el agente promueve o explota negocios del empresario por cuenta del agenciado empresario y no por su cuenta propia, en cambio en el contrato atípico 
denominado de distribución se lleva a cabo mediante el riesgo y por cuenta propia del mismo distribuidor y no por cuenta y riesgo del empresario".

El contrato comúnmente e impropiamente denominado de "distribución" no se encuentra tipificado como tal en nuestra ley. Es en realidad un contrato de suministro con pacto de distribución, no obstante lo anterior, para los efectos del presente ensayo será referido como contrato de distribución" (Holguín Neira \& Pombo abogados, 2008).

El contrato de distribución es aquel por el que el distribuidor (concesionario) se obliga a adquirir, comercializar y revender, a nombre y por cuenta propia, los productos del fabricante, productor o principal (concedente) en los términos y condiciones de reventa que este señale. El empresario tendrá la facultad de imponer al distribuidor determinadas obligaciones sobre la organización del negocio para la comercialización y reventa de productos. (Arce Gargollo, 2007)

Haciendo un paralelo entre uno y otro contrato podemos determinar los siguientes puntos:

"En el contrato de agencia el agente actúa por cuenta del empresario y puede hacerlo a nombre de este cuando se le concede la representación. En el contrato de distribución, el distribuidor actúa por su cuenta y en su propio nombre. El contrato de agencia es un contrato de gestión de intereses ajenos; el de distribución es un contrato traslativo de dominio en el 
que el distribuidor compra y adquiere los productos para revenderlos por su cuenta al consumidor, bajo las condiciones que le impone el empresario. Se asemejan en que ambos contratos son de duración, de colaboración entre empresario y agente o distribuidor y se celebran entre comerciantes independientes". (Arce Gargollo, 2007)

La planificación comercial es otro de los elementos que ha pretendido la doctrina aplicar con la finalidad que el contrato se tipifique, para ello se requiere la configuración de este elemento, a través de cláusulas que establecen precios unitarios, régimen de mercados, programas de publicidad, obligatoriedad de tener establecimiento abierto, stock de una determinada cantidad de mercaderías, etc.

De la misma manera en la estipulación que normalmente efectúan los comerciantes como distribución se establece el margen de reventa, esto se refiere a que la remuneración del distribuidor, consiste en la diferencia entre el precio de compra y el de venta de las mercaderías distribuidas. El precio de reventa puede ser estipulado o no por el fabricante o importador.

Es indiscutible un aspecto de aplicación legal tanto en la agencia comercial como en el contrato de distribución el cual hace referencia a la exclusividad que a diferencia de la agencia este puede estar o no estipulada en el contrato. Puede ser bilateral, cuando el fabricante se compromete a no efectuar ventas en territorio 
del distribuidor, y éste último, a no comerciar productos que compitan con los del distribuido) o unilateral, (cuando sólo afecta a una sola de las partes).

El contrato de distribución permite tener como característica identificadora la delimitación de la zona de distribución, la ejecución del objeto del contrato tiene delimitada una zona territorial, es decir, un espacio geográfico determinado para la ejecución de la distribución y el desarrollo normal del margen de ventas.

A diferencia del contrato de agencia comercial el contrato de distribución permite la estipulación en cuanto al tiempo de duración del contrato, usualmente, es prolongado, de larga duración, pero nada obsta a que se pacte un tiempo inferior.

Ahora bien el estudio comparativo doctrinal desde el punto de vista de las responsabilidades jurídicas surgidas de los contratos de distribución permite diferenciar claramente al mismo del contrato de agencia comercial.

Siendo así la doctrina nacional ha identificado como obligaciones del distribuido los siguiente: la entrega de los bienes al distribuidor en la cantidad, tiempo y forma previsto, o a pedido del distribuidor, dependiendo de lo pactado, permiten identificar la relación jurídica de dependencia que éste presenta con el distribuidos a diferencia de la agencia comercia de la independencia en la 
ejecución de las actividades tendientes a la comercialización de las mercancías encargadas.

Otra característica diferenciadora entre la distribución y la agencia comercial es aquella basada en que en el contrato de distribución es la no realización por sí o por terceros de operaciones en la zona del distribuidor, y evitar que otros terceros las realicen. Todo dependerá si se ha pactado la exclusividad.

Además de las anteriores el distribuidor se obliga a entregar el producto de manera idónea informando al empresario de todas aquellas variaciones que presenten los precios de los bienes y servicios distribuidos en la zona determinada.

La verdadera diferencia se evidencia en los efectos jurídicos que se desprenden de la actividad realizada por el comerciante contratado por el empresario, para que realice la actividad de comercialización, teniendo en cuenta que la actividad desarrollada en el objeto contractual de la agencia comercial, es una actividad independiente y estable, de forma remunerable y toda la actuación desplegada por el agente se desarrolla por cuenta del agenciado, esta tipificación desarrolla efectos a la vida jurídica del empresario así el agente no haya asumido la representación de este, generando un traslado indiscutible a la esfera patrimonial del empresario, por lo cual es llamado a asumir los riesgos propios de 
la actividad como la pérdida o no venta de las mercancías y demás que nazcan en el actuar del agente.

Por otro lado la doctrina y la jurisprudencia arbitral colombiana a identificado de manera certera y contundente manifestando que "la actuación por cuenta ajena, es esencial a la agencia, (....) de igual manera estipula que son dos los criterios elementales para la configuración del concepto de agencia comercial (i) la atribución patrimonial de una determinada actuación y consecuente con lo anterior (ii) la identificación de quien ha de soportar los riesgos, o reportar las ventajas de una especifica actuación jurídica" (Luna Bisbal, et al 2007).

Además de observar los elementos de la naturaleza del contrato, requisitos y demás características particulares es necesario e indispensable verificar el elemento determinante que le permite su identificación y peculiaridad. La corte suprema de justicia estableció que el elemento determinante en la agencia comercial es la promoción del negocio que realice el agente. Lo que para la luz del derecho implica la carga que debe llevar a cuestas el agente en el sentido de abrir el mercado y lograr la promoción del negocio o encargo.

Dicho en otros términos, lo determinante en la agencia comercial no son los contratos que el agente logre perfeccionar, concluir o poner el hecho mismo de la promoción del agenciado, sino el hecho mismo de la promoción del negocio de este, lo que supone una ingente actividad dirigida en un comienzo a la conquista 
de los mercados y de la potencial clientela, que debe luego ser canalizada por el agente para darle continuidad a la empresa desarrollada a través de el por el agenciado, de forma tal que una vez consolidada, se preserve o aumente la clientela del empresario, según el caso. De allí la importancia que tienen en este tipo de negocios jurídicos las clausulas que establecen un plazo de duración, pues ellas, amén de blindar el vinculo contractual frente a terminaciones intempestivas, le otorgan estabilidad a la relación, no solo en beneficio del agente sino también del agenciado.

La globalización y la internacionalización han llevado entonces a que de una u otra forma, las empresas extranjeras como las nacionales pretendan desconocer en ciertos negocios, el carácter de orden publico por encima de la voluntad de las partes. En el caso de Comestibles ricos VS distribuidora Marvill limitada. Se pacto un contrato de distribución, pero el tribunal decidió declarar la naturaleza del contrato celebrado como el de agencia comercial.

"El pasado mes de marzo se publicó el laudo arbitral en relación con la agencia comercial existente entre dos empresas colombianas: Comestibles Ricos y distribuidora Marwill limitada, en la que se conmino a la primera a pagar a su ex agente más de 30.0000 de pesos en indemnización por la terminación unilateral del contrato sin justa causa, no obstante no haberse firmado un acuerdo de agencia comercial, y en su lugar, haberse establecido un contrato de distribución en el que Marwill renunciaba a su 
derecho legal de solicitar cualquier indemnización por la terminación unilateral del contrato"(Mancero, 2007).

El panorama brindado en el análisis del contrato de agencia comercial ofrece diversas discusiones en el sentido de otorgar validez jurídica a la autonomía de la voluntad, siempre y cuando esta no contrarié o vaya en dirección opuesta a normas de orden público, como resultado de la renuncia de una de las partes al cobro de la cesantía comercial establecida en la ley.

Bajo los principio de buena fe contractual, autonomía de la voluntad, las partes pueden obligarse de tal modo que el clausulado inmerso en el contrato no trunque el deseo o animo contractual de las partes, ya que de allí deriva el inicio de las relaciones comerciales.

No obstante al interés reciproco en obtener una ganancia o ventaja se pretenda desviar bajo figuras contractuales similares y usualmente conocidas en el argot comercial, a fin de evitar sanciones jurídicas a determinados comportamientos contractuales, sin necesidad de resquebrajar el ordenamiento jurídico colombiano.

Es cierto que el ejercicio del comercio es dinámico, y que el derecho pretende ir al compas de regular las relaciones jurídicas; sin embargo no se pueden olvidar los lineamientos, pautas e interpretación asignados por la doctrina 
y jurisprudencia que otorgan la relevancia legal a la naturaleza del negocio jurídico, dejando a un lado la práctica de comportamientos que de uno u otra forma aparejan una desventaja en el extremo contractual.

\section{REFERENCIAS}

Arce Gargollo, J. (2007). Contratos Mercantiles Atípicos, décimo segunda edición. México: Edit. Porrúa S.A

Arrubla Paucar, A. (2005), Sentencia, Exp. 11001-3103-023-1997-24529-01, Corte Suprema de Justicia. Sala de Casación Civil.

Bonivento Jiménez, J. A. (1999). Contratos mercantiles de intermediación. Segunda edición. Bogotá D.C: Ediciones librería del profesional

Broseta Pont, M. (2003). Laudo Arbitral, D.E.I.P. Baranquilla

Cárdenas, J. P. (2003). Laudo Arbitral, D.E.I.P. Barranquilla

Díaz Rueda, R. M.(2008). Expediente No 0800131030061998-00171-01, corte suprema de justicia sala de casación civil. 
Gómez Martínez, E. (2005). Agencia Comercial: Autonomía de la voluntad y responsabilidad. Revista Portafolio Pág.1 recuperado el 23 de marzo de 2010 de www.portafolio.com.co

Holguín Neira \& Pombo abogados.(2008). Diferencias sustanciales entre el contrato de agencia y el contrato atípico de distribución recuperado el 21 de marzo de 2010 de http://www.hnpabogados.com.co/Boletin\%20Vl/Diferencia\%20Contrato\%20 Agencia\%20y\%20Distribuci\%C3\%B3n.pdf

Jaramillo, C. I. (2005). Expediente No 7504. corte suprema de Justicia

Luna Bisbal, D. Et Al (2007).Laudo arbitral

Mancero, G. (2007). ¿Preponderancia de los derechos de la gente en el contrato de agencia comercial? Recuperado de www.cavelier.com

Murcia Ballen, H. (1984). Arbitramento de Cheltex Ltda. Vs. Empresa Regional de Comunicaiones Celulares de La Costa Atlántica S.A. Celcaribe, Sentencia, M.P G.J No 2415

Presidencia de La Republica de Colombia. (1971). Código de Comercio Decreto 410.Diario Oficial N0 33339 
Sentencia del 9 de septiembre de 1929, G.J, tomo XXXVII, Pág. 128

Tafur Galvis, A.(2006). Sentencia C-990. Corte Constitucional

Vall De Ruten Ruiz, J. (Arbitro Único). (2003). Laudo Arbitral, Marketing Comunicaciones Pérez Navarro \& Cía. Sociedad En comandita VS Marketing Directo Galan Lozada y Cia sociedad En comandita 